\title{
A INTERCULTURALIDADE NA EDUCAÇÃO DO JOVEM APRENDIZ: UM ESTUDO DE CASO DE TECNOLOGIA DIGITAL NA INTEGRAÇÃO DE AGENTES NA APRENDIZAGEM PROFISSIONAL
}

\author{
INTERCULTURALITY IN YOUNG APPRENTICE EDUCATION: ACASE \\ STUDY OF DIGITAL TECHNOLOGY IN INTEGRATING AGENTS IN \\ PROFESSIONALLEARNING
}

Aline Maria da Conceição Vieira de Oliveira

Universidade Iguaçu - UNIG e Faculdades Souza Marques

https://orcid.org/0000-0002-5416-1622

Data de submissão: 02/03/2019

Data de aprovação: 10/04/2019

\begin{abstract}
RESUMO
A educação do jovem aprendiz na legislação brasileira possui lacunas que podem ser supridas pelas novas tecnologias digitais, que podem contribuir para a integração dos agentes envolvidos, bem como, a partir dos resultados da integração entre os agentes, subsidiar políticas públicas para o Jovem Aprendiz, cuja faixa etária vai de 14 a 24 anos. A importância deste Aplicativo se dá no campo da Instrução Normativa que desconsiderou alguns aspectos da proteção a esse jovem. É sobre esses aspectos normativos e sobre o papel das tecnologias digitais para suprir lacunas de interação e comunicação na formação do Jovem Aprendiz que se debruça este artigo.
\end{abstract}

Palavras-Chaves: Jovem Aprendiz. Tecnologia Digital. Instrução Normativa 146

Comunicação. Interação.

\begin{abstract}
The education of the young apprentice in Brazilian legislation has gaps that can be overcome by the new digital technologies, which can contribute to the integration of the agents involved, as well as, from the results of the integration between the agents, to subsidize public policies for the Young Apprentice, whose age ranges from 14 to 24 years. The importance of this Application is given in the field of Normative Instruction that disregarded some aspects of the protection of the young apprentice. It is about these normative aspects and about the role of digital technologies to fill gaps in interaction and communication in the formation of the Young Apprentice, which is addressed in this article.
\end{abstract}

Keywords: Young Apprentice; Digital Technology; Normative Instruction 146;

Communication, Interaction 


\section{INTRODUÇÃO}

A instrução Normativa é expedida pelos superiores dirigentes dos órgãos, seja pelo representante maior do órgão em questão, ou pelo dirigente delegado para tais atribuições para emitir as Instruções Normativas sobre sua extensão. Desta feita, a Instrução Normativa diz o que os agentes daquele órgão público devem seguir, executar, fazer ou respeitar, bem como a Instrução Normativa descreve a respeito das atribuições que devem ser seguidas por aqueles parâmetros específicos naquele ato administrativo. Em síntese, a Instrução Normativa é um ato administrativo o qual deve estar em consonância com todo o ordenamento jurídico (OLIVEIRA, 2018).

O Estatuto da Criança e Adolescentes 1990 comunica que as crianças devem ser assistidas pelo poder público, pela família e a sociedade vedando o uso da nomenclatura "menor" referindo-se as crianças e adolescentes. Há garantia de proteção dos direitos dos jovens por meio das leis que regem nosso país?

Este artigo traz a visão de uma professora e psicopedagoga sobre o projeto Jovem Aprendiz, que, como cidadã, exerce o papel de assistir a criança e o jovem, conforme lhe permite o ECA 1990. Não é uma visão de uma bacharela em Direito, mas de uma profissional da área da Educação, no exercício da cidadania e que possui uma visão interdisciplinar.

A Constituição Federal, a Consolidação das Leis do Trabalho - CLT e a Instrução Normativa 146/18 nos informam que é proibido qualquer tipo de trabalho a menores de dezesseis anos, salvo como Jovem Aprendiz a partir dos 14 até o limite de 24 anos de idade. As atividades laborais também têm suas restrições, pois não podem prejudicar as funções emocionais, psíquicas, mentais e sociais dos jovens.

A Instrução Normativa consolida atos editados pelo Poder Executivo Federal, que dispõem sobre a temática do aprendiz, e especifica os direitos adquiridos para os jovens na idade de 14 a 24 anos que galgam uma vaga no mercado de trabalho, buscando experiência profissional, mas anseiam finalizar seus estudos. Alguns pontos dentro desta jornada constitucional e normativa para inserção do jovem no mundo do trabalho para o Jovem Aprendiz merecem uma reflexão, frente à Instrução Normativa $146 / 2018$ e às novas tecnologias digitais.

\section{REFERENCIAL TEÓRICO}

\subsection{0 aprendiz na instrução normativa 146}

A Instrução normativa 146, de 25 de julho de 2018, elenca as entidades para formação técnico-profissional metódica: I - os serviços nacionais de aprendizagem, assim identificados: Senai, Senac, Senar, Senat e Sescoop; II - as escolas técnicas e agrotécnicas de educação; e III - as entidades sem fins lucrativos que tenham por objetivos a assistência ao adolescente e à educação profissional, registradas no conselho municipal dos direitos da criança e do adolescente. A Formação metódica inclui também as entidades sem fins lucrativos, que serão formadoras deste elenco de jovens entre 14 a 24 anos.

Este artigo pretende mostrar que, ao elaborar a instrução normativa do Jovem Aprendiz, o gestor não salvaguardou a causalidade, que ficou fragilizada. Percebe-se que houve interferências na elaboração da instrução, uma vez que há um descompasso 
entre aprendizado, jovem aprendiz, competências ou habilidades a serem desenvolvidas na empresa e salta aos olhos a grande evasão do projeto. Não há integração entre os agentes, eles não se juntam na lei e é só.

O Brasil é um país imenso, e o número de jovens que precisam de uma oportunidade para aprender é grande. É evidente que não se pode colocar toda esta necessidade nas mãos do gestor, mas poder-se-ia pensar um pouco mais no Jovem Aprendiz. O Brasil precisa contar com gestores e empresários dispostos a assumir o seu papel de formadores de boas práticas no trabalho. Não há outro lugar para aprender a profissão.

Um aspecto importante é a contratação indireta por entidades formadoras sem fins lucrativos, como se vê abaixo, e que evidencia a necessidade de integração desta pluralidade de agentes.

Art. $9^{\circ} \mathrm{A}$ contratação de aprendizes por entidades sem fins lucrativos que tenham por objetivo a assistência ao adolescente e a educação profissional, conforme faculdade prevista no art. 431 da CLT, exige a formalização prévia de contrato ou convênio entre o estabelecimento que deve cumprir a cota da entidade contratante.

A tecnologia pode integrar estes agentes em prol do Aprendiz, possibilitando uma formação mais adequada e futuras políticas públicas na área, devido à natureza informacional das tecnologias digitais.

$\S 1^{\circ} \mathrm{Na}$ hipótese de contratação indireta prevista no caput, a entidade sem fins lucrativos assume a condição de empregador de forma simultânea ao desenvolvimento do programa de aprendizagem, cabendo-lhe:

$[\ldots]$

$\S 2^{\circ} \mathrm{O}$ estabelecimento, na contratação indireta, obriga-se a proporcionar a experiência prática para a formação técnicoprofissional do aprendiz.

Ter um acompanhamento integrado, através de uma tecnologia digital, complementa o acompanhamento deste jovem, que precisa entender o significado de sua participação num processo tão amplo, para que em sua mente não se instale a anomia, pela falta de percepção do todo.

Na contratação indireta, a contratante é a organização sem fins lucrativos - a formadora, e o jovem vai aprender a prática da profissão em outra empresa, que é parceira contratada da organização sem fins lucrativos, que contratou o jovem. As entidades sem fins lucrativos que tenham por objetivo a assistência ao adolescente e à educação profissional, devem estar inscritas no Cadastro Nacional de Aprendizagem e registradas no Conselho Municipal dos Direitos da Criança e do Adolescente CMDCA.

Outra questão é a contratação de jovens aprendizes em função proibida, conforme está regulamentado nos artigos 11 e 12 da instrução normativa 146 .

Art. 11. A idade máxima de vinte e quatro anos é condição de extinção automática do contrato de aprendizagem, não se aplicando tal critério às pessoas com deficiência, para as quais a contratação é possível mesmo após essa idade.

Art. 12. Nos estabelecimentos em que sejam desenvolvidas atividades em ambientes ou funções proibidas a menores de dezoito anos, devem ser contratados aprendizes na faixa etária entre dezoito e 
vinte e quatro anos ou aprendizes com deficiência maiores de dezoito anos.

$\mathrm{Na}$ verdade, não houve uma preocupação com o que é proibido para jovens entre 18 e 24 anos, pois nos estabelecimentos em que sejam desenvolvidas atividades em ambientes ou funções proibidas a menores de dezoito anos, devem ser contratados aprendizes na faixa etária entre dezoito e vinte e quatro anos ou aprendizes com deficiência maiores de dezoito anos. Neste artigo 12, nota-se um estranhamento do gestor com o tema jovem com deficiência.

A Instrução Normativa 146 regulamenta que as atividades práticas da aprendizagem em locais insalubres ou perigosos a que se refere a instrução normativa, deverão ser designadas aos jovens de dezoito a vinte e quatro anos. Há um estranhamento na instrução normativa do Jovem Aprendiz; estes aspectos deveriam ser tratados de uma outra forma, não deveria haver esta possibilidade de trabalho para o jovem aprendiz, porque, certamente, existem outras formas de ensinar o jovem aprendiz a trabalhar. Para suprir de forma adjunta esta lacuna, a tecnologia digital aqui proposta busca integrar os agentes responsáveis pela formação e proteção do jovem aprendiz.

\subsubsection{A interculturalidade entre os agentes}

É neste contexto, que somente o direito de trabalhar com regras específicas aos jovens de 14 a 24 anos não tem sido o suficiente para que a educação profissional, em um contexto amplo, chegue a esses jovens de forma adequada e completa. Analisando a legislação, não encontramos artigo de lei que solicite a comunicação continua das partes envolvidas no programa. Esses agentes sociais não conversam entre si para assegurar êxito no programa. Eles não conhecem as culturas que permeiam o programa, a realidade da vivência dos jovens dentro e fora do projeto. Há um desconhecimento sobre o real contexto social desse jovem e de como ele chegou até o projeto. A real necessidade dessas famílias que fazem parte do programa é uma peça desconhecida de todos. São vários os fatores que precisam ser vistos e revistos por esses agentes que são peças fundamentais do projeto "Jovem Aprendiz". A ausência de conhecimento relacional das partes que compõem o programa cria conflitos de informações, principalmente para os jovens aprendizes, que se relacionam com todos os envolvidos.

Com tantas particularidades na educação técnico-profissional, torna-se necessário o conhecimento das culturas das entidades que fazem o Projeto ter vida. Assim, a proposta é que o jovem seja ouvido e atendido dentro de suas necessidades que ocorrem no decorrer de suas atividades laborais, teóricas e práticas. $E$ neste contexto, a tecnologia digital aqui referenciada tem esse objetivo, ou seja, a tecnologia digital é intercultural.

Segundo Vasconcelos (apud FLEURI, 2005)

o conceito de interculturalidade, usado para indicar um conjunto de propostas de convivência democrática entre diferentes culturas, buscando a integração entre elas sem anular sua diversidade, ao contrário, "fomentando o potencial criativo e vital resultante das relações entre diferentes agentes e seus respectivos contextos" (Fleuri, 2005). O termo tem origem e vem sendo utilizado com frequência nas teorias e ações pedagógicas, mas saiu do contexto educacional e ganhou maior amplitude passando a referir-se também 
às práticas culturais e políticas públicas. Este termo diferencia-se de outro bastante usado no estudo da diversidade cultural que é o da multiculturalidade que indica apenas a coexistência de diversos grupos culturais na mesma sociedade sem apontar para uma política de convivência".

A interculturalidade pode auxiliar na prática e no andamento do projeto apresentando aos agentes a democracia que se encontra quando a interculturalidade faz parte do processo. O respeito às diferenças culturais é um dos pilares preservados com essa prática, observando a criatividade e a forma de crescimento. $O$ crescimento acontece por esperar o respeito às particularidades de cada cultura existente no projeto. A convivência já existe, mas é preciso democratizar esse convívio para que a diversidade se complemente, formando um ambiente saudável e construtivo. A interculturalidade abraça o convívio benéfico aos seus adeptos. Ela envolve os saberes, as culturas, o diferente, o novo.

Nas políticas públicas, que é o caso do Projeto Jovem Aprendiz, para que haja de forma global a interculturalidade entre os agentes tão diferentes, com culturas tão arraigadas à sua existência, será necessário o entrelaçamento dos saberes. Conhecer as forças, as deficiências, a fragilidade e a resiliência um dos outros para que se respeitem enquanto instituições e se ajudem, focando em um bem comum, os jovens. O apoio de tecnologias, para que os agentes possam interagir entre si é um ponto de partida que faz com que as possibilidades sejam levantadas e analisadas.

A tecnologia tem crescido em todos os setores e, no projeto, poderá ser um meio e não um fim para que haja integração entre os agentes, pois ela já vem unindo povos, línguas e nações, para quem está longe ou não tão perto assim. E é por meio dela que a interação acontece. As mídias sociais têm o poder de unir os que estão longe e criar vínculos nos ambientes virtuais, que é o lugar onde a sociedade tem se encontrado com mais frequência.

Losso (2013, p. 32) afirma que

Podemos considerar os ambientes virtuais de aprendizagem como espaços construídos para interação entre sujeitos, ou seja, nenhum ambiente, seja virtual ou real, consegue por si só estabelecer reais vínculos a não ser pela intensidade das interações e mediações.

Os espaços virtuais têm sido um lugar rico em diversidades, de culturas de toda parte. Ela tem ofertado às novas gerações hábitos e costumes diferentes, influenciando diretamente em suas escolhas, modificando a comunicação e as relações, realocando o antigo e dando espaço ao novo.

As relações construídas pelas mídias sociais são carregadas de estigmas; uns dizem que são rasas, por conta da distância física, outros defendem a solidez, por poder estar perto mesmo estando longe.

[...] os instrumentos do ciberespaço permitem a famílias dispersas, assim como às pessoas geograficamente afastadas do lar geográfico de sua comunidade nacional, manter contato estreito com seu grupo de pertencimento, principalmente com as novas tecnologias móveis (LEMOS; LÉVY, 2014, p. 105).

Como a tecnologia tem oferecido a oportunidade de interação e integração entre as pessoas, entende-se que ela, por meio de dispositivo móvel, pode auxiliar pessoas a estarem em contato contínuo, relacionando-se em tempo real, fazendo links que talvez pessoalmente não tivesse. Pode auxiliar no preenchimento das lacunas que 0 "Direito", a lei, não preencheu dentro do projeto Jovem Aprendiz, que é trabalhar a 
unidade do projeto e dos objetivos a serem alcançados, unificando saberes para que o público pertencente ao projeto encontre singularidade em suas atividades. $O$ relacionamento entre os agentes do projeto poderá ter o mesmo êxito de comunicação, interação, respeito que existem em pares pertencentes, como diz Lemos.

A tecnologia virá para que as relações se estreitem e que a interculturalidade ocorra.

Segundo Boechat, Cabral e Souza (2007, p. 27):

As novas tecnologias da informação e comunicação, que conectam pessoas via internet, estão, de fato, à disposição daquelas que queiram estabelecer contato, manter a comunicação e deixar ou não a relação interpessoal ganhar consistência, ou seja, tornar-se menos "líquida" ao propiciar a formação de vínculos que tendem a permanecer na duração do tempo, na medida do interesse e/ou necessidade de seus usuários.

2.1.2 A proposta de uma tecnologia digital que integre os agentes e supra lacunas de informação

O uso de um aplicativo para integrar os agentes que participam de forma conjunta no programa de formação do Jovem Aprendiz, tem como objetivo suprir as lacunas das normas e permitir que os agentes possam interagir e buscar soluções conjuntas para a evasão do Jovem Aprendiz e também contribuir para a sua formação no trabalho, reiterando as competências e habilidades que empresas e escolas devem proporcionar a fim de que os jovens desenvolvam durante o tempo que passam em suas dependências.

Vive-se, em sociedade, um momento de fragilidades social, uma vez que os jovens são altamente expostos às tecnologias e a dominam, mas em suas carências afetivas e econômicas acabam muitas vezes por serem presas fáceis por tecnologias conduzidas por pessoas pouco confiáveis, como no caso de endereços de locais na Deep Web.

Note-se que, embora fosse melhor não criar a possibilidade de trabalho em local que possa comprometer a saúde ou a integridade moral do jovem aprendiz, houve preocupação do gestor de integrar o Ministério do Trabalho com o empregador do jovem aprendiz quanto a este tipo de arranjo, como se evidencia no artigo 12 da Instrução Normativa 146, incisos I e II. Na contratação indireta, evidencia-se também a responsabilidade da empresa formadora nestes arranjos.

No entanto, a tecnologia digital permite uma interação entre os agentes em prol do jovem aprendiz: a instituição qualificadora pode acompanhar, por meio de seus cursos, o desenvolvimento das habilidades e competências tanto em suas dependências quanto nas dependências onde o jovem desenvolve as práticas de trabalho. A escola e a empresa podem interagir reportando ausências injustificadas do jovem, e o próprio jovem terá o seu diário de bordo, reportando problemas que porventura esteja enfrentando.

O papel da tecnologia digital aqui é evidenciar o diário de bordo como um componente fundamental deste Aplicativo, que busca suprir o Jovem Aprendiz com um instrumento de reporte de problemas no trabalho. Ou seja, a tecnologia digital dá voz ao Jovem Aprendiz no relacionamento com os agentes: empresa formadora, empregadora e escola, protegendo-o no exercício de sua atividade no posto de trabalho, trabalhando. 
Veja o esquema abaixo:

Figura 1- Fluxos de informação entre processos do programa Jovem Aprendiz

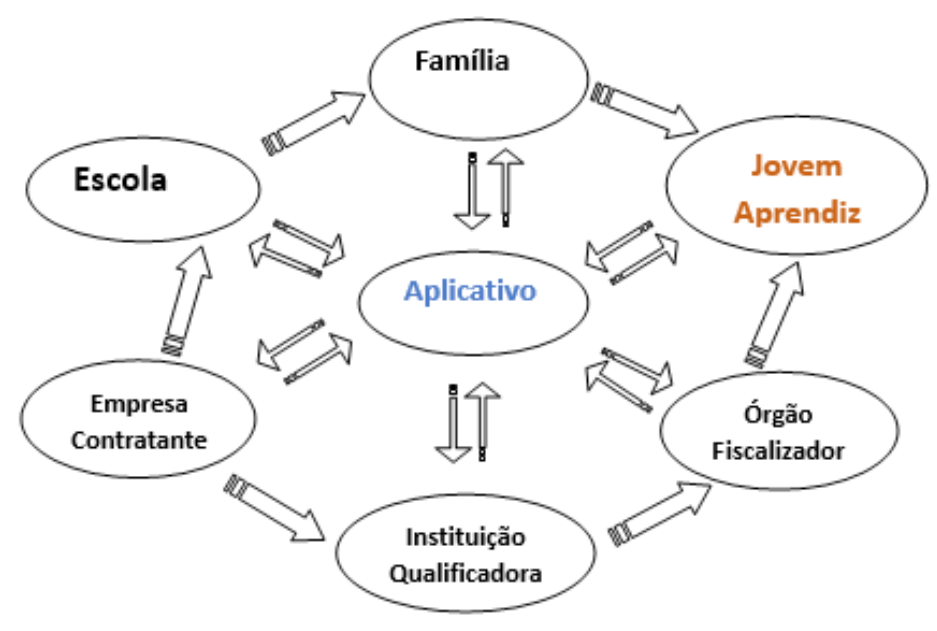

Fonte: Oliveira (2019)

Com a utilização da tecnologia digital, a interculturalidade ocorrerá, fazendo com que os agentes sociais se integrem e interajam entre si em prol do jovem. Pode surgir desta interculturalidade entre os agentes uma protoforma de propostas de políticas públicas para a formação do Jovem Aprendiz.

\section{METODOLOGIA}

A Metodologia empregada é qualitativa e considerou uma pesquisa documental em normas brasileiras para fazer uma avaliação da Instrução Normativa 146, de 2018, que não traz a necessária interculturalidade entre os agentes responsáveis pela formação do jovem aprendiz, ou seja, não há na norma nenhuma ação comunicativa e interacional que integre os agentes: instituição qualificadora, empregadora e escola. Também mostramos o papel da tecnologia digital de suprir essas lacunas interacionais.

\section{CONSIDERAÇÕES FINAIS}

As críticas que foram feitas aqui à Instrução Normativa 146 podem ser supridas pela empresa formadora, em conjunto com a escola e a empresa, através de uma tecnologia digital que integre esses agentes, em prol do trabalho e bem-estar do aprendiz. É evidente que há aspectos que continuam obscuros, como atividades em ambientes ou funções proibidas a menores de dezoito anos, para as quais devem ser contratados aprendizes na faixa etária entre dezoito e vinte e quatro anos ou aprendizes com deficiência, mas espera-se que a empresa formadora levante-se em prol do Jovem Aprendiz.

Os documentos legais rezam que a contratação do aprendiz deverá ser efetivada diretamente pelo estabelecimento que se obrigue ao cumprimento da cota de aprendizagem ou, supletivamente, pelas entidades sem fins lucrativos e, na hipótese de contratação de aprendiz diretamente pelo estabelecimento que se obrigue ao cumprimento da cota de aprendizagem, este assumirá a condição de empregador, 
hipótese em que deverá inscrever o aprendiz em programa de aprendizagem a ser ministrado pelas entidades indicadas na lei e na instrução normativa.

A contratação de aprendiz por intermédio de entidade sem fins lucrativos, para fins do cumprimento da obrigação prevista somente deverá ser formalizada após a celebração de contrato entre o estabelecimento e a entidade sem fins lucrativos, no qual, entre outras obrigações recíprocas, serão estabelecidas as seguintes: I - a entidade sem fins lucrativos, simultaneamente ao desenvolvimento do programa de aprendizagem, assumirá a condição de empregador, com todos os ônus dela decorrentes, e assinará a Carteira de Trabalho e Previdência Social do aprendiz, na qual anotará, no espaço destinado às anotações gerais, a informação de que o contrato de trabalho específico decorrerá de contrato firmado com determinado estabelecimento para fins do cumprimento de sua cota de aprendizagem; e II - o estabelecimento assumirá a obrigação de proporcionar ao aprendiz a experiência prática da formação técnico-profissional metódica a que este será submetido.

Pode-se ver que são muitos agentes, e a empresa contratante também tem que proporcionar aos jovens a ida à escola, caso não tenha concluído seus estudos, pois esse é um dos pré-requisitos para que ele faça parte do programa. Terá que ser apresentada a declaração escolar ou o certificado de conclusão de curso no momento em que faz a inscrição para a vaga de aprendiz na empresa que o contrata.

O contrato de trabalho para o jovem aprendiz é especial, pois ele tem tempo determinado, e o empregador encaminha o jovem para um curso compatível com sua prática sob supervisão de uma instituição qualificadora; assim poderá adquirir formação técnico-profissional. Todas as empresas, exceto as empresas de pequeno porte e microempresas, denominadas "empresas simples", não têm a obrigatoriedade de cumprir a cota de $5 \%$ a $15 \%$ de jovens.

A carga horária de atividades laborais é de até seis horas por dia, sendo vedada hora extra, compensação de horas, banco de horas. O jovem que já tiver concluído os estudos poderá trabalhar até oito horas por dia.

Todos esses direitos precisam ser acompanhados, assistidos, para que a lei se cumpra; para isso o Ministério do Trabalho, com suas delegacias regionais do trabalho, fiscaliza se as empresas estão em conformidade com a lei e se os jovens estão usufruindo os direitos que a lei os oferece.

A bem da verdade, ao invés de só evitar a evasão, a tecnologia digital depositada na Plataforma Proximal na Unicarioca, integra conhecimento, agentes envolvidos e o jovem aprendiz, trazendo soluções inovadoras, criando novos saberes sobre o jovem aprendiz. A tecnologia digital integrando os agentes, pode atuar de forma supletiva para que os jovens aprendizes possam ter o direito de aprender.

\section{REFERÊNCIAS}

BETTO, Frei. Essa escola chamada vida. 8. ed. São Paulo: Ática, 1994. 95 p. Depoimentos ao repórter Ricardo Kotscho.

BOECHAT, leda Tinoco; CABRAL, Heldeliza Lacerda; SOUZA, Carlos Henrique. Relacionamentos virtuais e família: enlaces interculturais. Revista Internacional de Folkcomunicação. V.15, n.35, 2017. Disponível em: http://www.revistas.uepg.br/ index.php/folkcom/article/view/228 Acesso em: 15 abr. 2019.

BRASIL. Instrução Normativa 146/2018. Diário Oficial da União. Brasília, DF, 01 ago. 2018. 
CANDAU, Vera Maria. Didática crítica intercultural: aproximações. Petrópolis: Vozes, 2012. $251 \mathrm{p}$.

CRIANÇAS e adolescentes: indicadores sociais. Rio de Janeiro: IBGE, 1987.

FLEURI, Reinaldo Matias. Educação intercultural: mediações necessárias. Rio de Janeiro: DP\&A, 2003.

FREIRE, Paulo. Medo e ousadia : cotidiano do professor. 7. ed. São Paulo: Paz e Terra. 1997. 223 p.

ILLERIS, Knud. Teorias contemporâneas da aprendizagem. Porto Alegre: Penso, 2013. 278 p.

LOPES, Priscila Romero. Cultura na palma da mão: potencialidades do aplicativo "Minha Espanha" para aprender sobre a cultura espanhola. Dissertação.

Disponível em: https://repositorio.unesp.br/handle/11449/154962. Acesso em: 15 fev. 2019.

OLIVEIRA, Iolanda. A lei e a instrução normativa: a força da instrução normativa. Disponível em: http://www.rochamarques.com.br/site/wp-content/uploads/ pdf/a-lei-e-a-instrucao-normativa.pdf Acesso em: 15 fev. 2019.

SÍNTESE de indicadores sociais: uma análise das condições de vida da população brasileira. Rio de Janeiro: IBGE, 2016.

SOUZA, Anna Carolina de. Jovem aprendiz: uma análise da política pública e suas consequências no desenvolvimento dos jovens. Disponível em https://repositorio.ufsc. br/xmlui/bitstream/handle/123456789/173329/Monografia\%20a\%20Anna\%20Carolina. pdf?sequence=1\&isAllowed=y. Acesso em: 15 fev. 2019. 